\title{
LETTERS
}

\section{Comparing family medicine residency training in Canada and the United Kingdom}

Wendy Glauser's CMAJ News article mentions that the United Kingdom has a longer training program for family medicine and a primary care system that outperforms Canada's. ${ }^{1}$ I wonder where the evidence is to support that claim.

Although family medicine training in the UK takes a minimum of 3 years, the trainees in the UK work shorter hours than trainees in Canada, owing to the European Working Time Directive, which restricts a working week to a maximum of 48 hours. $^{2}$ This does not mean that the UK trainees have more relaxed training; the European Working Time Directive causes inadequate work coverage and burnout among trainees. ${ }^{3}$ Trainees are overstretched and thus have minimal time to develop their knowledge and skills. ${ }^{4}$ Moreover, each rotation in a UK training program takes 4-6 months, compared with 4 weeks in Canada, thereby limiting the trainee's exposure to only a few specialties. ${ }^{5}$ A general practice trainee in the UK can finish training without having worked in psychiatry, obstetrics and pediatrics, all of which are core rotations in the Canadian training system.

The UK specialty training programs have a "winnowing" process, ${ }^{6}$ with a $50 \%$ pass rate in the Royal College examinations. ${ }^{7}$ Some applicants to family medicine are dropouts from specialty programs, with years of experience in hospital training. But this creates a negative image for family physicians, who are mislabelled as failures off the specialty consultant ladder. ${ }^{8}$ Is this how Canadian family physicians want to be labelled?

Canadian primary care is highly praised by the British who have experienced the systems in both countries. ${ }^{9}$ Should we learn from a foreign system that has been strongly criticized by its own physicians?

\section{Eugene Y.H. Yeung MD MSc}

Resident physician, University of Ottawa, Ottawa, Ont.

Cite as: CMAJ 2019 February 4;191:E140. doi: $10.1503 / \mathrm{cmaj} .71131$

\section{References}

1. Glauser W. Longer family medicine residency being considered for Canada. CMAJ 2018;190:E1235-6.

2. Rodriguez-Jareño MC, Demou E, Vargas-Prada S, et al. European Working Time Directive and doctors' health: a systematic review of the available epidemiological evidence. BMJ Open 2014;4: e004916.

3. Cowie CJA. European Working Time Directive may contribute to fatigue. BMJ 2013;347:f5360.

4. Cheshire A, Hughes J, Lewith G, et al. GPs' perceptions of resilience training: a qualitative study. Br J Gen Pract 2017;67:e709-15.

5. Yeung EYH. Apples and oranges: comparing residency models in the UK and North America. BMJ 2018;360:k59.

6. Wilson CR, Bordman ZN. What to do about the Canadian Resident Matching Service. CMAJ 2017; 189:E1436-47.

7. Exam pass rates. London (UK): Membership of the Royal Colleges of Physicians of the United Kingdom; 2018. Available: www.mrcpuk.org/ mrcpuk-examinations/results/exam-pass-rates (accessed 2018 July 1).

8. Wass V, Gregory S. Not 'just' a GP: a call for action. Br J Gen Pract 2017;67:148-9.

9. Dr PK. Moving to Canada to work as a GP was the best decision I've ever made. London (UK): The Guardian; 2015 Sept. 7. Available: www. theguardian.com/healthcare-network/views-from -the-nhs-frontline/2015/sep/07/moving-to-canada -to-work-as-a-gp-was-the-best-decision-ive-ever -made (accessed 2018 Oct. 17).

Competing interests: None declared. 